\title{
Contextualized music listening: playlists and the Mehrabian and Russell model
}

\author{
Amanda E Krause* and Adrian C North
}

\author{
* Correspondence: \\ Amanda.Krause@curtin.edu.au \\ School of Psychology and Speech \\ Pathology, Curtin University, GPO \\ Box U1987, Perth, WA 6845, \\ Australia
}

\begin{abstract}
The present research considered everyday music listening in the context of eight situations, classified as high or low on Mehrabian and Russell's (1974) PleasureArousal-Dominance (PAD) dimensions. Completing a questionnaire, 344 participants considered the music they would select and created a playlist for a given situation. The music selected by participants (as playlists) for these eight situations differed along two dimensions, namely arousing and aesthetic. Rather than selecting music that would moderate arousal (Berlyne, 1971), results indicated that participants employed an arousal-optimization strategy. There were also differences in the music selected across situations on the aesthetic dimension. The findings also suggest that music chosen for situations is subject to injunctive norms, such that there was considerable variation between the music chosen for listening to on public transport or when washing dishes, whereas music selected for a wedding was perceived as more homogeneous. While previous research has considered music preference in terms of pleasure and arousal, the apparent role of injunctive norms may be related to dominance and requires additional research. More generally, the results indicate that Mehrabian and Russell's PAD dimensions offer a useful framework for considering the relationship between music and the environmental context in which it is experienced.
\end{abstract}

Keywords: Playlists; Contextualized listening; Music preference; Everyday; Pleasure-Arousal-Dominance model

As a result of technological advancements, and particularly the invention of mobile computing devices (e.g., mp3 players and smartphones), people exert greater control than ever before over how, when, and where they experience music (Heye and Lamont, 2010; Juslin et al. 2008; Krause et al. 2013; North and Hargreaves, 2008; Sloboda et al. 2009). The digitization of music has altered consumption practices (Avdeeff, 2012), particularly by allowing more interactivity (Kibby, 2009) so that listeners are no longer constrained by, for instance, albums and track orders (Molteni and Ordanini, 2003). Listening via playlists contrasts with listening to an album or via shuffle (i.e., a playback option that randomly orders the presentation of a set of songs - Cunningham et al. 2006). Playlists allow users more control over the specific music heard in that users specify both the song content and sequence of the selected songs. With an increasing amount of listening occurring via digital devices (Avdeeff, 2012; Leong and Wright, 2013), playlists represent a common method of listening to music (Komulainen et al. 2010; Krause, 2010).

(c) 2014 Krause and North; licensee Springer. This is an Open Access article distributed under the terms of the Creative Commons Attribution License (http://creativecommons.org/licenses/by/4.0), which permits unrestricted use, distribution, and reproduction in any medium, provided the original work is properly credited. 
Playlists may reflect users' attempts at mood regulation (Cunningham et al., 2006; Heye and Lamont, 2010), and appear to be the preferred playback option for listening that occurs while carrying out other activities (Kamalzadeh et al. 2012). Leong and Gram (2011) go so far as to suggest that a new type of listening strategy has arisen from greater use of playlists, in which the listener regards music as a resource and actively uses a mobile device based on his/her needs: the music is regarded as an adjustable soundtrack that supports his/her identity, mood, activities, and surroundings. This supports DeNora's (2000) assertion that people are able to act as 'personal DJs' who are aware of what music they need to hear in different situations and at different times, and who define that 'right' music in part by how it fits the purpose or situation. In the modern era, then, the playlist is an appropriate unit of analysis to use in researching everyday music listening.

\section{Everyday listening}

Research has established that everyday music listening takes place in varying contexts, and that people use music to accompany varying activities (Krause et al., 2013; North et al. 2004; Sloboda and Juslin, 2010). However, there is a lack of research concerning the factors that influence contextual listening choices (Kamalzadeh et al., 2012). The determinants of everyday listening remain the subject of little research, and there is similarly poor theoretical understanding.

Prior research concerning music preference has adopted the approach of experimental aesthetics. Much of this has concerned the putative inverted- $U$ relationship between the degree of pleasure and arousal evoked by music (Kellaris, 1992; North and Hargraves 1997; North and Hargreaves, 1996b). Berlyne's (1971) theory argues that there is an inverted-U between liking for music and the degree of arousal it evokes, so that moderately arousing music is liked most. Laboratory research has frequently (although not always) confirmed this inverted-U relationship. However, the concern of the present research is whether it holds regarding everyday listening situations (North and Hargreaves, 2008), as such situations may impose polarized levels of arousal or otherwise be subject to more socially-defined norms for music listening. North and Hargreaves (2000) found that individuals preferred 'high-arousal music' during aerobic exercise activity but 'low-arousal music' during guided relaxation, such that music selections reflected an arousal-polarization rather than -moderation strategy. However, when stating preferences after relaxing or exercising, participants' music preferences suggested attempts at moderating their arousal levels (North and Hargreaves, 2000). Further evidence that the predictions of Berlyne's theory are not confirmed in naturalistic settings is provided by North and Hargreaves (1996c) who found that preferred musical characteristics for a situation were those that augmented the affective qualities of the situation: highly arousing situations, such as exercising, were associated with descriptors that implied increased arousal; whereas situations representing a low degree of arousal, such as before going to bed, were associated with descriptors that would reduce arousal levels. Thus, preferred music would have further polarized participants' degree of arousal, rather than moderating it. It is likely that different arousal states may be considered appropriate for different situations (Hargreaves and North, 2010), such that preference, and the role of arousal in this, cannot be considered independently of the listening situation. Indeed, research considering playlist construction specifically 
has indicated that individuals consider mood, genre, rhythmic quality, volume, composition, and tempo (among other characteristics) when creating and managing playlists (Kamalzadeh et al., 2012; Stumpf and Muscroft, 2011) and that awareness of the context (or the situation/ activity) in which the playlist will be used is included as an element of a "good" playlist (Fields and Lamere, 2010).

Moreover, recent research which considered devices and selection choices related to everyday listening (Krause et al., 2013; Krause et al. 2014; Krause et al. in press) goes further than the earlier work on appropriateness by indicating that control and choice concerning the music in question are themselves important contextual factors. Using music listening devices that allow for personal input, such as mobile mp3 players, was associated with more positive moods and consequences than were devices that do not permit such control, suggesting that dominance may be crucial in one's response to music encountered during everyday life. Berlyne's theory cannot account simply for the role of music in allowing some degree of control over the listening environment. However, one approach that can is Mehrabian and Russell's (1974) Pleasure-Arousal-Dominance (PAD) model.

Mehrabian and Russell's (1974) environmental psychology theory states that human emotional responses result from variations in pleasure, arousal, and dominance (hereafter 'the PAD dimensions') in the situation in question. Pleasure and arousal are characterized in a manner similar to the earlier work on experimental aesthetics. However, the model adds a third factor, dominance, which refers to the extent to which the individual in question is able to exert control over his/her environment. Such a dimension seems directly analogous to the earlier finding concerning the importance of choice and control in contextualized music listening. According to the theory, these three dimensions are necessary and sufficient to characterize a person's feelings, which are influenced both by the person and environmental stimuli. In turn, a person's emotional state then regulates his or her behavior in a situation (Mehrabian and Russell, 1974).

This model provides a comprehensive conceptualization of the environment using the pleasure, arousal, and dominance domains (see previous research by, e.g., Hines and Mehrabian, 1979; Yani-de-Soriano and Foxall, 2006). Previous research demonstrates that these three domains (to varying degrees and with varying degrees of specificity) are pertinent to understanding the responses of an individual within a particular situation. As such, an individual's behavior in a situation can be characterized in terms of approach and avoidance behaviors. Approach behaviors concern moving physically towards an environment, interacting with it, and achieving one's objectives therein, while avoidance behaviors demonstrate the opposite, such as leaving and not engaging in an environment (Donovan and Rossiter, 1982; Yalch and Spangenberg, 2000). Previous research has successfully characterized the environment in terms of PAD: for instance, North and Hargreaves (1996a) examined how the music played in a cafeteria was associated with customers' physical movements within and emotional responses towards the immediate situation.

In terms of the PAD domains, pleasure increases approach behaviors, and any aspect of the environment may generate pleasant stimulation and cause approach, including the individual or learned associations between the environment and other pleasureinducing factors (Mehrabian and Russell, 1974). For instance, a person enjoying the company of friend will likely find the situation more pleasing due to the pleasant companionship even though that companion is not an inherent aspect of the particular 
environment. Arousal level also mediates approach-avoidance behaviors (Donovan and Rossiter, 1982; Hines and Mehrabian, 1979; Mehrabian and Russell, 1974). Extremely high or low levels of arousal are avoided while environments of moderate arousal levels best encourage approach behaviors. As with pleasure, arousal is determined both by the individual and the environment (Mehrabian and Russell, 1974). Mehrabian and Russell (1974) were uncertain as to how dominance related to approach-avoidance behaviors, due to a lack of evidence. In fact, much of the research has ignored dominance altogether, such that its influence on approach and avoidance behaviors remains uncertain. However, Yani-de-Soriano and Foxall (2006) critically assessed the inconsistent research concerning dominance and concluded that it is a "valid emotional dimension and, as such, is an integral part of the measurement of the emotion-eliciting qualities of environments and mediates approach-avoidance behavior". Moreover, research on emotions supports the role of control (Fontaine et al., 2007; Goudbeek and Scherer, 2010); specifically endorsing using a model that includes a domain characterized by appraisals of control (i.e., dominance), because a two-dimensional model (such as pleasurearousal models) misses major sources of variation in emotions (Fontaine et al., 2007).

Therefore, this framework offers a promising means of exploring individuals' daily music interactions because the pleasure and arousal dimensions can accommodate (at least to some extent) earlier findings within experimental aesthetics, but the additional dimension of dominance means that it can also account for more contemporary evidence concerning the individual's control over and interactions with his or her context.

The aim of this research is to investigate those factors underlying music listening in different situations. Firstly, as everyday listening situations vary, it seems appropriate to attempt to characterize these differences in terms of Mehrabian and Russell's PAD framework. It similarly seems appropriate to attempt to address responses to these situations in terms of those theories outlined above. Specifically, as Berlyne's theory attempts to explain all aesthetic responses, we might expect to find an inverted- $\mathrm{U}$ relationship between ratings of pleasure and arousal assigned to the listening situation itself. Similarly, given the arguments above concerning the importance of choice, we might expect to find a positive relationship between ratings of pleasure and dominance assigned to the listening situations. As such, this leads to three preliminary hypotheses, as follows:

H1: Everyday music listening situations will be differentiated in terms of pleasure, arousal, and dominance, such that different situations can be classified as "high" and "low" in terms of pleasure, arousal, and dominance.

H2: There will be an inverted- $U$ relationship between ratings of pleasure and arousal assigned to the situations.

H3: There will be a positive relationship between the pleasure and dominance ratings assigned to the situations.

Assuming that differences between the listening situations do exist on the PAD dimensions, then we might therefore expect the music selected for those situations to vary accordingly. On the basis of previous evidence concerning preference and arousal, we expect that musical choices may differ for specific situations on the basis of arousalbased goals therein. If listeners are in a situation that requires high arousal, such as 
exercising, they should wish to hear with descriptors that would increase arousal (such as loud and rhythmic); whereas situations in which a low degree of arousal is desirable, such as before going to bed, should be associated with a wish to hear music with descriptors that would reduce arousal levels (such as quiet and relaxing). This difference in arousal should also be reflected structurally in the beats per minute (BPM) of the music. BPM is an index of arousal apparent to the listener and easily quantified. Thus, the mean BPM of the music selected to accompany jogging should be significantly higher than the mean BPM for music selected for listening to before going to sleep.

However, factors other than arousal may be salient also. In particular, playlist construction has been shown to be based on a number of features, including context (Kamalzadeh et al., 2012; Stumpf and Muscroft, 2011). North and Hargreaves (1996c) found that preferred music for a situation often appears to reflect the affective qualities of the situation in a manner that simply could not be accounted for in terms of arousal, and which instead appeared to relate to cognitive judgments regarding the perceived function or appropriateness of the music. For instance, music selected for a romantic dinner might be characterized as being sensual; music for a cocktail party might be characterized as sophisticated; and music selected before sleep might be characterized as beautiful.

Additionally, the music experienced in some situations/contexts might be subject to strong injunctive norms, which refer to the perception of what music ought to be present in a certain situation and the functions it should fulfill. This applies both in terms of whether music should be played or not (i.e., the degree of choice and control that the individual has over whether music can be heard at all) and of expectations as to what style or even pieces of music should be played (i.e., the specific nature of any music present). Thus, a situation might be considered to be subject to strong versus weak injunctive norms. For example, there would be a strong injunctive norm to play music at a party but not during a lecture. Moreover, in most western ceremonies, at a wedding it is likely that a bride will walk down the aisle to the Wedding March. This strong injunctive norm dictates the specific nature of the music to which the wedding attendees are exposed. In contrast, when driving a car one has considerable volition over whether music is played at all and if so over the nature and function of that music, such that this situation is subject to weak injunctive norms. These injunctive norms might reasonably be expected to translate to perceived differences in what music is considered preferable/appropriate in specific contexts. Therefore, it should be considered as an aspect of contextualized listening.

This argument suggests that, in addition to finding variation between situations in terms of dominance ratings, we might also find that injunctive norm differences mean that some situations give rise to similar musical experiences across individuals whereas other situations are associated with individuals listening to very different music selected on far more idiosyncratic bases. Therefore, we expect to find greater similarity between people's playlists in situations that are subject to stronger injunctive norms and less similarity in people's playlists in situations that are subject to weaker injunctive norms.

This leads to four further hypotheses, as follows:

H4: Preferred music for "high arousal" situations will be characterized by descriptors that imply increased arousal, whereas music preferred for "low arousal" situations will be associated with descriptors that would reduce arousal levels. 
H5: The BPM of the music selected to accompany "high arousal" situations will be significantly higher than the BPM of music selected for "low arousal" situations.

H6: The preferred music for a situation will be characterized in terms of adjectives that reflect the context in which it is to be experienced.

H7: There will be differences between situations in ratings of how similar individuals believe their playlist to be to those playlists made by other people for the same situation.

\section{Applying the PAD Model to Everyday Situations}

A manipulation check was conducted in order to characterize the situations addressed by the present research. Four hundred participants (50 per situation) independently completed Mehrabian and Russell's (1974) Pleasure-Arousal-Dominance measure for one of the eight situations. Participants completed the 18-item PAD measure either on paper or online. The eight situations included four selected as likely involving high or low levels of arousal, and also four situations likely subject to strong or weak injunctive norms concerning music (which refers to the degree that the situation suggests/commands certain music be listened to by the individual). The eight situations (adapted from North and Hargreaves, 1996c) were a house party with friends (putatively high arousal), jogging with an mp3 player (putatively high arousal), before going to sleep (putatively low arousal), after a long day of work (putatively low arousal), a wedding (putatively strong injunctive norm), a posh cocktail reception (putatively strong injunctive norm), doing the washing up/ ironing (putatively weak injunctive norm), and commuting on public transportation (putatively weak injunctive norm). The PAD measure presents participants with 18 items (six per dimension), presented as bipolar adjective pairs on seven-point Likert scales, for which they are asked to indicate how they feel in the given situation. Mean pleasure, arousal, and dominance scores were then calculated for each situation (note that due to the direction of the PAD measure's scoring, high levels of pleasure, arousal, and dominance are represented by lower means). Cronbach's alpha for the pleasure, arousal, and dominance dimensions was $.89, .88$, and .86 respectively.

Pleasure, arousal, and dominance scores across the situations were analyzed with three separate maximum likelihood mixed effects linear regression models as implemented through SPSS's Generalized Linear Mixed Models (GLMM; $\alpha=.017$ ). GLMM represents a special class of regression model, which allows both random and fixed effects to be modeled; and can model outcome variables with non-normal distributions.

The analyses concerning pleasure and arousal were significant: pleasure $F(7,387)=$ $15.08, p<.001, \eta_{\mathrm{p}}^{2}=.214$; arousal $F(7,384)=16.08, p<.001, \eta_{\mathrm{p}}^{2}=.225$. The analysis regarding dominance was of borderline significance, $F(7,387)=2.47, p=.017, \eta_{\mathrm{p}}^{2}=.035$. Deviation contrasts, which compared each situation's mean to the overall mean, were examined to identify those situations that gave rise to significantly higher or lower scores across the different situations. As such, this analysis identified "high" and "low" situations in terms of each of pleasure, arousal and dominance. These results, confirming Hypothesis 1, are presented in Tables 1 and 2, and demonstrate that the PAD dimensions are able to distinguish meaningfully between the situations.

As illustrated by the significant deviation contrasts in Table 2, "high pleasure" situations were a house party, at a wedding, and before going to sleep; in contrast, doing the washing up/ironing, after a long day, and commuting on public were "low pleasure" 
Table 1 Means, standard errors, and 95\% confidence intervals of the GLMM analyses concerning the eight situations' average pleasure, arousal, and dominance values

\begin{tabular}{|c|c|c|c|c|c|c|c|c|c|}
\hline \multirow[b]{2}{*}{ Situation } & \multicolumn{3}{|c|}{ Pleasure } & \multicolumn{3}{|c|}{ Arousal } & \multicolumn{3}{|c|}{ Dominance } \\
\hline & $M$ & $S E$ & $95 \% \mathrm{Cl}$ & $M$ & $S E$ & $95 \% \mathrm{Cl}$ & $M$ & $S E$ & $95 \% \mathrm{Cl}$ \\
\hline Posh cocktail reception & 2.72 & 0.14 & {$[2.45,2.99]$} & 3.60 & 0.16 & {$[3.29,3.90]$} & 3.47 & 0.15 & {$[3.18,3.77]$} \\
\hline House party & 2.25 & 0.13 & {$[2.00,2.50]$} & 3.12 & 0.13 & {$[2.87,3.38]$} & 3.72 & 0.13 & {$[3.46,3.98]$} \\
\hline After a long day & 3.14 & 0.12 & {$[2.89,3.38]$} & 4.23 & 0.20 & {$[3.83,4.63]$} & 3.64 & 0.16 & {$[3.34,3.95]$} \\
\hline $\begin{array}{l}\text { While doing the washing } \\
\text { up/ironing }\end{array}$ & 3.63 & 0.19 & {$[3.26,4.00]$} & 4.51 & 0.18 & {$[4.16,4.87]$} & 3.56 & 0.14 & {$[3.29,3.83]$} \\
\hline At a wedding & 2.09 & 0.12 & {$[1.86,2.32]$} & 3.09 & 0.17 & {$[2.76,3.42]$} & 3.90 & 0.19 & {$[3.52,4.27]$} \\
\hline Before going to sleep & 2.35 & 0.11 & {$[2.13,2.57]$} & 4.43 & 0.21 & {$[4.03,4.84]$} & 3.90 & 0.17 & {$[3.57,4.23]$} \\
\hline $\begin{array}{l}\text { While commuting on } \\
\text { public transportation }\end{array}$ & 3.54 & 0.17 & {$[3.21,3.87]$} & 4.69 & 0.18 & {$[4.33,5.06]$} & 4.07 & 0.17 & {$[3.73,4.41]$} \\
\hline $\begin{array}{l}\text { While jogging with an } \\
\text { mp3 player }\end{array}$ & 2.90 & 0.16 & {$[2.59,3.22]$} & 3.15 & 0.16 & {$[2.84,3.46]$} & 3.34 & 0.13 & {$[3.07,3.60]$} \\
\hline
\end{tabular}

Note. $\mathrm{N}=400$ (50 per situation); $\mathrm{SE}=$ Standard error; $\mathrm{Cl}=$ Confidence interval.

situations. "High arousal" situations included a house party with friends, jogging with an mp3 player, and at a wedding, while "low arousal" situations were after a long day, doing the washing up/ironing, before going to sleep, and commuting on public transportation. Further, jogging with an $\mathrm{mp} 3$ player was a "high dominance" situation and commuting on public transportation was a "low dominance" situation.

To address H2, a GLMM analysis tested for a relationship between arousal (entered as the predictor variable) and pleasure (entered as the outcome). The responses to the arousal items on the Mehrabian and Russell measure (rated as 1-7) were recoded as -3 to +3 respectively, the mean was then calculated, and then the negative sign was removed. Thus, by removing the negative sign, high values represent ratings towards the poles of the scale, so that a negative relationship is indicative of a real-terms inverted-U relationship. The result was non-significant $(\beta=-0.07[-0.25,0.11], t(386)=-0.79$, $\left.p=.431, \eta^{2}=.002\right)$. Therefore, there was no evidence of an inverted-U relationship between ratings of pleasure and arousal.

Table 2 Deviation contrast results from the GLMM analyses regarding the eight situations' average pleasure, arousal, and dominance values

\begin{tabular}{|c|c|c|c|c|c|c|c|c|c|c|c|}
\hline \multirow[t]{2}{*}{ Deviation Contrasts } & \multicolumn{4}{|c|}{ Pleasure } & \multicolumn{4}{|c|}{ Arousal } & \multicolumn{3}{|c|}{ Dominance } \\
\hline & $t$ & & $95 \% \mathrm{Cl}$ & $\eta^{2}$ & $\bar{t}$ & & $95 \% \mathrm{Cl}$ & $\eta^{2}$ & $t$ & $95 \% \mathrm{Cl}$ & $\eta^{2}$ \\
\hline $\begin{array}{l}\text { Posh cocktail reception - } \\
\text { mean }\end{array}$ & -0.79 & & {$[-0.36,0.15]$} & .002 & -1.74 & & {$[-0.55,0.03]$} & .008 & -1.60 & {$[-0.50,0.05]$} & .007 \\
\hline House party - mean & -4.68 & $* * *$ & {$[-0.82,-0.34]$} & .054 & -5.63 & $* * *$ & {$[-0.99,-0.48]$} & .076 & 0.13 & {$[-0.23,0.27]$} & .000 \\
\hline After a long day - mean & 2.73 & ** & {$[0.09,0.53]$} & .019 & 2.04 & * & {$[0.01,0.74]$} & .011 & -0.40 & {$[-0.34,0.23]$} & .000 \\
\hline $\begin{array}{l}\text { While doing the washing } \\
\text { up/ironing - mean }\end{array}$ & 4.73 & $* * *$ & {$[0.47,1.14]$} & .055 & 3.92 & $* * *$ & {$[0.33,0.99]$} & .038 & -1.04 & {$[-0.40,0.12]$} & .003 \\
\hline At a wedding - mean & -6.49 & $* * *$ & {$[-0.96,-0.52]$} & .098 & -4.80 & $* * *$ & {$[-0.07,-0.45]$} & .057 & 1.14 & {$[-0.15,0.54]$} & .003 \\
\hline $\begin{array}{l}\text { Before going to sleep - } \\
\text { mean }\end{array}$ & -4.34 & $* * *$ & {$[-0.70,-0.26]$} & .046 & 3.05 & $* *$ & {$[0.21,0.95]$} & .024 & 1.31 & {$[-0.10,0.51]$} & .004 \\
\hline $\begin{array}{l}\text { While commuting on } \\
\text { public transportation - } \\
\text { mean }\end{array}$ & 4.83 & $* * *$ & {$[0.42,1.00]$} & .057 & 4.94 & $* * *$ & {$[0.51,1.17]$} & .060 & 2.31 & {$[0.06,0.68]$} & .014 \\
\hline $\begin{array}{l}\text { While jogging with an } \\
\text { mp3 player - mean }\end{array}$ & 0.50 & & {$[-0.22,0.37]$} & .001 & -4.71 & $* * *$ & {$[-1.00,-0.41]$} & .055 & -2.82 & {$[-0.62,-0.11]$} & .020 \\
\hline
\end{tabular}

Note. DF $=387$ for Pleasure and Dominance, and 384 for Arousal; ${ }^{*} p<.05,{ }^{* *} p<.01,{ }^{* * *} p<.001$. 
To address H3, a GLMM analysis was carried out in which pleasure was entered as the predictor variable and dominance as the outcome variable. As predicted, the results demonstrated a statistically significant positive relationship $(\beta=0.31[0.20$, 0.42 ], $\left.t(388)=5.75, p<.001, \eta^{2}=.079\right)$, indicating that feeling in control is related to feelings of pleasure.

\section{Method}

Participants

While 468 individuals completed a portion of the questionnaire, data analysis was performed using the responses from the 344 participants (73.50\% of total; 43 participants per situation) who nominated 10-12 pieces of music as requested. Of these 344 individuals, $207(61.10 \%)$ were female. Participant ages ranged from 16-64 years $(M=24.26$, $M d n=22, S D=7.48$ ).

Individuals were approached in person on a university campus to complete the questionnaire. Additionally, an online version of the questionnaire (created using Remark Web Survey software) and was publicized via advertisements placed around a university campus as well as via social media, online research listings, and the first author's website. Mean responses to each variable were calculated separately for the online- and paper-based samples. The correlation between these two data sets was .99. Therefore, the two sets of data were pooled in subsequent analyses. All participants were required to have access to a personal music collection (in any media format, including cloud/ streaming subscriptions) and to be familiar with playlist creation. Participation was voluntary, and some university students received course credit for their participation through the host University's research participation program.

\section{Materials}

\section{Background information}

Participants reported their age and sex, and answered three questions about their degree of engagement with music. The latter involved answering an open-ended question about their level of music education and experience, reporting the number of hours they listened to music on average daily, and rating how important they considered music to be in their life on a seven-point scale $(1=$ not at all to $7=$ extremely $)$.

\section{Playlist creation}

Individuals were randomly presented with one of the eight hypothetical music listening situations and asked to nominate a playlist of 10-12 songs to listen to therein (stating the full title and artist for each song). The same eight situations were investigated, namely a house party with friends, jogging with an $\mathrm{mp} 3$ player, before going to sleep, after a long day of work, a wedding a posh cocktail reception, doing the washing up/ ironing, and commuting on public transportation.

\section{Playlist questions}

Using seven-point scales $(1=$ not at all, $7=$ extremely), individuals rated the extent to which each of 24 music descriptors characterized the music chosen for the situation in question. These descriptors (taken from North and Hargreaves, 1996c) were familiar, sad, strong rhythm, attention-grabbing, can dance vigorously to it, happy, sensual, 
lilting, beautiful, natural/fresh, expresses profound emotions, sentimental, nostalgic, sophisticated/classy, exotic, quiet, loud, romantic, moody, inspiring/majestic, relaxing/ peaceful, invigorating, exciting/festive, and strong ethnic roots.

Participants also rated how similar they believed their playlist would be to that produced by other people for the same situation (hereafter referred to as the 'playlist similarity rating') and to what degree they considered their choices to be defined by prevailing musical norms for the specific situation (henceforth, 'constrained choice rating') on seven-point Likert scales (1 = unique/ original, 7 = the same; and $1=$ not at all, 7 = completely, respectively). Lastly, participants made two ratings indicating how often they made playlists and listened to music via playlist, using seven-point scales $(1=$ never and $7=a$ lot) for each.

\section{Procedure}

After reading the participant information and consent form, individuals answered the questions about themselves, nominated their playlist for the situation in question, and then answered the playlist questions. Randomization of the eight situations was achieved in the online questionnaire by having the participants select an answer to a non-pertinent question (i.e., selecting the name of one of Jupiter's moons) following the background questions, and by manually randomizing the paper surveys.

\section{Results}

\section{Music Descriptors}

Hypotheses 4 and 6 predicted respectively that preferred music would be characterized by arousal level and in terms of adjectives reflecting the context in which it is to be experienced. To test this, participants' ratings of the 24 musical descriptors were first subjected to factor analysis. Varimax rotation of the principal components solution produced two factors that accounted for $42.44 \%$ of the total variance (see Table 3). The two factors were labeled arousing and aesthetic respectively, and appear consistent with previous findings by North and Hargreaves (1996c).

Two separate GLMM analyses $(\alpha=.025)$ considered whether scores on the two factors respectively varied by situation. In these analyses, each music descriptor factor was entered separately as the dependent variable, while situation was the fixed factor (with eight levels). The two analyses were significant: arousing $F(7,244)=21.68, p<.001$, $\eta_{\mathrm{p}}^{2}=.383$; and aesthetic $F(7,244)=9.07, p<.001, \eta_{\mathrm{p}}^{2}=.206$. Deviation contrasts were examined to identify which situations gave rise to scores that differed from the overall mean. Results are presented in Tables 4 and 5 .

Preferred music for two high arousal situations, jogging with an mp3 player and a house party, was rated as significantly more arousing than for the overall average. In contrast, preferred music for before going to sleep (one of the low arousal situations) and at a posh cocktail reception was significantly less arousing than the overall average across all the situations. Therefore, the results appear to support $\mathrm{H} 4$ and prior research regarding the selection of music based on an attempt to achieve a desired state of arousal (e.g., North and Hargreaves, 2000).

As for the aesthetic dimension, which can be taken to reflect the emotional connotation of a situation as described in H6, the significant deviation contrasts indicate that this descriptor was significantly more important for the music experienced at a 
Table 3 Item loadings from the Varimax rotation principal components factor analysis on the $\mathbf{2 4}$ musical descriptor ratings

\begin{tabular}{|c|c|c|}
\hline \multirow[t]{2}{*}{ Item } & \multicolumn{2}{|c|}{ Factor } \\
\hline & 1 & 2 \\
\hline Loud & 0.82 & \\
\hline Invigorating & 0.81 & \\
\hline Attention-Grabbing & 0.81 & \\
\hline Strong Rhythm & 0.79 & \\
\hline Can dance vigorously to it & 0.79 & \\
\hline Exciting/Festive & 0.77 & \\
\hline Relaxing/Peaceful & -0.64 & \\
\hline Quiet & -0.74 & \\
\hline Sophisticated/Classy & & 0.75 \\
\hline Natural/Fresh & & 0.71 \\
\hline Sensual & & 0.64 \\
\hline Beautiful & & 0.64 \\
\hline Lilting & & 0.63 \\
\hline Exotic & & 0.61 \\
\hline Inspiring/Majestic & & 0.59 \\
\hline Romantic & & 0.56 \\
\hline Strong Ethnic Roots & & 0.52 \\
\hline \multicolumn{3}{|l|}{ Moody } \\
\hline \multicolumn{3}{|l|}{ Sad } \\
\hline \multicolumn{3}{|l|}{ Expresses profound emotions } \\
\hline \multicolumn{3}{|l|}{ Happy } \\
\hline \multicolumn{3}{|l|}{ Nostalgic } \\
\hline \multicolumn{3}{|l|}{ Sentimental } \\
\hline \multicolumn{3}{|l|}{ Familiar } \\
\hline Rotation Sums of Squared Loadings & 5.61 & 4.57 \\
\hline$\%$ of Variance & 23.38 & 19.06 \\
\hline
\end{tabular}

Note. Loadings $<.47$ are suppressed.

wedding and at a cocktail party. On the other hand, music after a long day, while commuting on public transport, during a house party, and while jogging was significantly less likely to be described by the aesthetic dimension when compared to the average across the situations.

Beats Per Minute (BPM)

BPM was used as an objective measure of arousal elicited by a piece of music nominated by participants. Nominations that did not state the artist/group were removed from the dataset (including, for example, classical submissions without a performer) as were works with multiple movements, as an accurate, single representative BPM could not be determined. Further, music that was not available in the iTunes and Amazon online catalogues was removed from the data set. Beat Monitor (a real-time BPM analyzer program available for purchase from the iTunes App Store) analyzed the BPM of each song using the online preview sound clip from the iTunes or Amazon online catalogues. As this program restricted analysis within a 91-180 BPM range, the 
Table 4 Means, standard errors, and 95\% confidence intervals of the GLMM analyses concerning the two musical descriptor factors, the playlist average BPM, and the playlist similarity rating

\begin{tabular}{|c|c|c|c|c|c|c|c|c|c|c|c|c|}
\hline \multirow[b]{2}{*}{ Situation } & \multicolumn{3}{|c|}{ 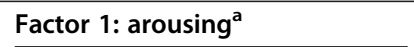 } & \multicolumn{3}{|c|}{ Factor 2: aesthetic ${ }^{a}$} & \multicolumn{3}{|c|}{ BPM mean $^{\mathbf{b}}$} & \multicolumn{3}{|c|}{ Similar list rating ${ }^{c}$} \\
\hline & Mean & Std. error & $95 \% \mathrm{Cl}$ & Mean & Std. error & $95 \% \mathrm{Cl}$ & $\bar{M}$ & Std. error & $95 \% \mathrm{Cl}$ & Mean & Std. error & $95 \% \mathrm{Cl}$ \\
\hline Posh cocktail reception & -0.38 & 0.15 & {$[-0.68,-0.08]$} & 0.58 & 0.16 & {$[0.26,0.90]$} & 118.78 & 1.92 & {$[115.01,122.55]$} & 2.35 & 0.19 & {$[1.97,2.73]$} \\
\hline House party & 0.48 & 0.14 & {$[0.20,0.76]$} & -0.45 & 0.21 & {$[-0.86,-0.04]$} & 124.88 & 1.45 & {$[122.02,127.74]$} & 3.70 & 0.24 & {$[3.23,4.16]$} \\
\hline After a long day & -0.17 & 0.16 & {$[-0.48,0.14]$} & -0.38 & 0.15 & {$[-0.67,-0.08]$} & 117.86 & 2.02 & {$[113.89,121.83]$} & 3.18 & 0.23 & {$[2.73,3.63]$} \\
\hline While doing the washing up/ ironing & 0.25 & 0.12 & {$[0.01,0.49]$} & 0.04 & 0.14 & {$[-0.24,0.32]$} & 121.62 & 1.73 & {$[118.21,125.03]$} & 3.14 & 0.22 & {$[2.71,3.57]$} \\
\hline At a wedding & 0.05 & 0.16 & {$[-0.27,0.36]$} & 0.78 & 0.18 & {$[0.44,1.13]$} & 112.21 & 1.86 & {$[108.54,115.87]$} & 3.28 & 0.23 & {$[2.83,3.73]$} \\
\hline Before going to sleep & -1.33 & 0.15 & {$[-1.63,-1.03]$} & 0.25 & 0.16 & {$[-0.07,0.56]$} & 108.26 & 2.12 & {$[104.08,122.44]$} & 3.51 & 0.21 & {$[3.10,3.93]$} \\
\hline While commuting on public transportation & 0.14 & 0.13 & {$[-0.11,0.40]$} & -0.46 & 0.13 & {$[-0.72,-0.20]$} & 122.22 & 2.03 & {$[118.22,126.22]$} & 2.92 & 0.20 & {$[2.53,3.31]$} \\
\hline While jogging with an $\mathrm{mp} 3$ player & 0.87 & 0.12 & {$[0.63,1.11]$} & -0.33 & 0.14 & {$[-0.60,-0.07]$} & 129.40 & 2.25 & {$[124.81,133.81]$} & 3.27 & 0.27 & {$[2.74,3.80]$} \\
\hline
\end{tabular}

Note. $\mathrm{Cl}=$ Confidence interval. 
Table 5 Deviation contrast results from the GLMM analyses regarding the GLMM analyses addressing the two musical descriptor factors, playlist average BPM, and the playlist similarity rating

\begin{tabular}{|c|c|c|c|c|c|c|c|c|c|c|c|c|c|c|c|c|}
\hline \multirow[t]{2}{*}{ Pairwise contrasts } & \multicolumn{4}{|c|}{ Factor 1: arousing ${ }^{a}$} & \multicolumn{4}{|c|}{ Factor 2: aesthetic ${ }^{a}$} & \multicolumn{4}{|c|}{ BPM mean $^{\text {b }}$} & \multicolumn{4}{|c|}{ Similarity rating $^{c}$} \\
\hline & $\bar{t}$ & & $95 \% \mathrm{Cl}$ & $\eta^{2}$ & $t$ & & $95 \% \mathrm{Cl}$ & $\eta^{2}$ & $t$ & & $95 \% \mathrm{Cl}$ & $\eta^{2}$ & $\bar{t}$ & & $95 \% \mathrm{Cl}$ & $\eta^{2}$ \\
\hline Posh cocktail reception - mean & -2.62 & $* *$ & {$[-0.65,-0.09]$} & .027 & 3.78 & $* * *$ & {$[0.28,0.88]$} & .055 & -0.35 & & {$[-4.16,2.91]$} & .000 & -4.46 & $* * *$ & {$[-1.18,-0.46]$} & .059 \\
\hline House party - mean & 3.70 & $* * *$ & {$[0.23,0.76]$} & .053 & -2.38 & * & {$[-0.82,-0.08]$} & .023 & 3.82 & $* * *$ & {$[2.66,8.30]$} & .042 & 2.42 & * & {$[0.10,0.96]$} & .018 \\
\hline After a long day - mean & -1.08 & & {$[-0.45,0.13]$} & .005 & -2.68 & $* *$ & {$[-0.66,-0.10]$} & .029 & -0.82 & & {$[-5.24,2.15]$} & .002 & 0.03 & & {$[-0.41,0.43]$} & .000 \\
\hline While doing the washing up/ ironing - mean & 2.20 & * & {$[0.03,0.49]$} & .019 & 0.27 & & {$[-0.23,0.30]$} & .000 & 1.34 & & {$[-1.03,5.47]$} & .005 & -0.14 & & {$[-0.43,0.43]$} & .000 \\
\hline At a wedding - mean & 0.39 & & {$[-0.23,0.35]$} & .001 & 4.80 & $* * *$ & {$[0.46,1.10]$} & .086 & -4.10 & $* * *$ & {$[-10.65,-3.75]$} & .048 & 0.52 & & {$[-0.31,0.53]$} & .001 \\
\hline Before going to sleep - mean & -9.38 & *** & {$[-1.60,-1.04]$} & .265 & 1.61 & & {$[-0.05,0.54]$} & .011 & -5.68 & *** & {$[-15.00,-7.28]$} & .087 & 1.72 & & {$[-0.05,0.74]$} & .009 \\
\hline While commuting on public transportation - mean & 1.26 & & {$[-0.09,0.40]$} & .006 & -3.64 & $* * *$ & {$[-0.72,-0.21]$} & .052 & 1.49 & & {$[-0.90,6.53]$} & .007 & -1.31 & & {$[-0.62,0.13]$} & .005 \\
\hline While jogging with an mp3 player - mean & 7.64 & $* * *$ & {$[0.66,1.11]$} & 193 & -2.60 & * & {$[-0.59,-0.08]$} & .027 & 4.85 & *** & {$[5.94,14.05]$} & .065 & 0.43 & & {$[-0.38,0.59]$} & .001 \\
\hline
\end{tabular}

\section{${ }^{\mathrm{a} D F}=244$.}

${ }^{\mathrm{b}} \mathrm{DF}=336$.
${ }^{\mathrm{c}} \mathrm{DF}=318$.

Note. ${ }^{*} \mathrm{p}<.05,{ }^{* *} \mathrm{p}<.01,{ }^{* * *} \mathrm{p}<.001$. 
operation of the program was monitored to identify any nominated pieces that fell outside this range so that they could be analyzed manually. A second, independent reviewer verified the BPM rating for the songs that were potentially misreported due to a BPM outside of this range (291 entries, or $7.64 \%$ of all nominated songs). Using the individual song BPMs, the overall playlist BPM mean was calculated for each participant's playlist.

A GLMM analysis $(\alpha=.05)$ was conducted to examine whether the mean BPM of the playlists (entered as the dependent variable) differed by situation (entered as the fixed factor). The overall model was significant, $F(7,336)=11.47, p<.001, \eta_{\mathrm{p}}^{2}=.193$; and deviation contrasts indicated a pattern of significant differences (see Tables 4 and 5). Similar to the results arising from participants' ratings of the music descriptors, a house party and jogging were situations for which mean BPM results were significantly higher than the average across all situations. In contrast, the mean BPM was significantly lower for the playlists created for use before going to sleep and at a wedding. Confirming the hypothesized pattern (H5), the results indicated that high arousal situations are associated with arousing music and slower, calming music was associated with low arousal situations.

\section{Injunctive Norms}

H7 predicted that ratings for 'playlist similarity' would differ because situations are subject to injunctive norms. A GLMM analysis $(\alpha=.05)$ examined the 'playlist similarity' ratings (entered as the dependent variable) in terms of the situation (the fixed factor). This analysis was significant: $F(7,318)=3.93, p<.001, \eta_{p}^{2}=0.08$; and deviation contrasts again highlighted the differences between situations (see Tables 4 and 5). The results indicate that playlist similarity for a house party was significantly higher than the average rating. In contrast, playlists created for a cocktail reception were rated as significantly less likely to be similar to those playlists created by other people. This supports $\mathrm{H} 7$, suggesting that the strength of the injunctive norms associated with certain situations could be shaping listening choices.

\section{Discussion}

In this study, everyday music listening was considered in the context of eight different situations. These everyday situations, which differed in terms of ratings of pleasure, arousal, and dominance, can be classified as high or low on the three domains. Thus, the results indicate that Mehrabian and Russell's PAD dimensions offer a useful framework for considering the relationship between music and the environmental context in which it is experienced. Therefore, subsequent analyses considered differences between the music selected (as playlists) for these eight situations.

Music choices for the situations were characterized along two dimensions, namely arousing and aesthetic. When considering how music choices for the situations are characterized, the arousing and aesthetic dimensions highlight the differences in the preferred music in various situations. The arousing dimension suggests that preferred music was characterized in part on the basis of arousal goals. Specifically, because the pattern of results showed that high arousal situations were associated with music rated as highly arousing (and low arousal situations were associated with preferred music that was significantly less arousing), it demonstrates that listeners are using arousal-optimization 
strategies, rather than necessarily using arousal-moderation strategies. Moreover the evidence from the BPM analysis reiterates the same pattern of preferring music with a higher BPM rate (equated to more arousing music) in high arousal situations and slower music (lower BPM/less arousing music) in low arousal situations. Participants were apparently choosing music to polarize their degree of arousal to a level that is consistent with the goals of the listening situation, rather than attempting to moderate their level of arousal.

The second, aesthetic descriptor dimension speaks to H6, providing a dimension on which preferred music for a given situation is also apparently characterized in terms of the perceived function of the music or in terms of a judgment of its appropriateness. Thus, this dimension suggests the importance of the beauty of the music as a criterion by which participants judged the relevance of that music for a particular situation. Furthermore, characterizations of the preferred music via the aesthetic dimension also reflected the pattern of findings that was obtained in terms of high and low pleasure: that is, 'beautiful' music was selected for situations with a clearer aesthetic component.

The present findings also have theoretical implications when viewed in the light of North and Hargreaves' (1996c) argument that the perceived appropriateness of music is an important predictor of in situ musical preferences. Specifically, the two factors discussed here, arousing and aesthetic, appear to represent the dimensions along which music can be characterized as "appropriate" for a situation. Moreover, as it is possible to map the results for aesthetic and arousal onto the PAD dimensions, this suggests that Mehrabian and Russell's model is a valuable means of understanding the relationship between the listening situation and musical preference.

The findings also suggest that music chosen for situations is subject to injunctive norms. For instance, while there was considerable variation between participants in the music chosen for listening to while on public transport or when washing dishes, music selected for a wedding was much more homogeneous. These findings indicate that the extent to which a person has control over the music they hear is an important variable, but also raises a question for discussion, namely how best to conceptualize this notion of dominance. The present findings indicate that attempts to use music to achieve a certain degree of arousal are one component of dominance, but also that there are other injunctive norms that also influence the choice of music to be heard in a particular context. To some extent, it is possible that music becomes an injunctive norm for the situation in question because it brings about a certain level of arousal, but also seems likely that numerous other cognitive factors also inform the process by which injunctive musical norms are formed. Thus, it is possible that injunctive norms might tap into the dominance dimension of the PAD model, although, clearly, further work is needed to better specify the components of dominance.

One particularly useful means of doing so may be to study listening over extended periods of time, using a smartphone app that allows collection of in situ ratings of the various possible contributors to dominance and in the light of play counts for particular pieces of music: the playlists created in the present research were constructed specifically for the study and not actually used in the prescribed situations. Additionally, websites that allow users to post and share playlists, for example, may offer a wealth of data to explore in terms of contextualized listening habits, and it may be of interest to carry out qualitative research that probes individuals' perception of what constitutes dominance. 
The present findings also raise a number of theoretical and methodological issues that might be addressed in future research. For instance, it could be relevant to consider the importance of the situation to the person concerned and his/her degree of experience of that situation. For instance, someone who regularly listens to music while jogging may have more specific ideas on the music to include than someone who does not exercise with music. This type of familiarity with using music for certain situations may influence someone's perceptions of both dominance and injunctive norms. Similarly, if the individual regard the situation as important (e.g., a wedding party) then we might expect that he/she would put considerably more effort into a playlist than in less important contexts (e.g., making dinner). Moreover, it may beneficial to consider traits of the individual listeners, such as the degree of importance of music to the individual concerned: a number of demographic and psychological characteristics (e.g., North, 2010; North and Davidson, 2013) might relate to people's preferences for music in different situations. Moreover, while the present research used BPM data as an objective measure of the arousal-evoking qualities of the music, there could be other objective measures (obtained from e.g., wearable exercise fitness devices) that could be employed to further explore contextualized listening.

Moreover, the present research also addresses two limitations of prior research. Firstly, although previously there has been a lack of research concerning the factors that influence contextual listening choices (Kamalzadeh et al., 2012), the arousing and aesthetic dimensions and consideration of injunctive norms begin to define the salient factors in contextualized music choices. Secondly, there remains little theoretical understanding of everyday music listening. To that end, the present results support recent findings suggesting that control is an important element of contextualized listening (e.g., Krause et al., 2013, 2014). Further, given the evidence that listeners appear to adopt arousaloptimization strategies (rather than arousal-moderation strategies as predicted by research on experimental aesthetics), Mehrabian and Russell's PAD dimensions seem to offer a viable theoretical model. Though additional research is needed to fully define dominance in terms of everyday music listening, the present results support the continued consideration of the PAD model.

Abbreviations

PAD: Pleasure-arousal-dominance; BPM: Beats per minute; GLMM: Generalized linear mixed model.

Competing interests

The authors declare that they have no competing interests.

Authors' contributions

AK and AN jointly developed the conception and design of the study. AK conducted data collection, analyzed and interpreted the data, and drafted the manuscript. AN assisted with the critical interpretation of the data and revision of the manuscript. Both authors read and approved the final manuscript.

\section{Acknowledgements}

The authors thank Robert Kane for assistance with statistical analyses.

Received: 16 April 2014 Accepted: 15 September 2014

Published online: 18 December 2014

References

Avdeeff, M. (2012). Technological engagement and musical eclecticism: An examination of contemporary listening practices. Participations: Journal of Audience \& Reception Studies, 9(2), 265-285.

Berlyne, DE. (1971). Aesthetics and psychobiology. New York: Appleton-Century-Crofts.

Cunningham, SJ, Bainbridge, D, \& Falconer, A. (2006). 'More of an art than a science:' Supporting the creation of playlists and mixes (Paper presented at the the Seventh International Conference on Music Information Retrieval (ISMIR 2006)). Victoria, Canada: University of Victoria. 
DeNora, T. (2000). Music in everyday life. Cambridge: Cambridge University Press.

Donovan, RJ, \& Rossiter, JR. (1982). Store atmosphere: An environmental psychology approach. Journal of Retailing, 58(1), 34-57.

Fields, B, \& Lamere, P. (2010). Finding a path through the juke box: The playlist tutorial (Paper presented at the 11th International Society for Music Information Retrieval Conference (ISMIR), August 9-13, 2010).

Fontaine, JRJ, Scherer, KR, Roesch, EB, \& Ellsworth, PC. (2007). The world of emotions is not two-dimensional. Psychological Science, 18(12), 1050-1057. doi: 10.1111/j.1467-9280.2007.02024.x.

Goudbeek, M, \& Scherer, K. (2010). Beyond arousal: Valence and potency/control cues in the vocal expression of emotion. Journal of Acoustical Society of America, 128(3), 1322-1336. doi:10.1121/1.3466853.

Hargreaves, DJ, \& North, AC. (2010). Experimental aesthetics and liking for music. In PN Juslin \& JA Sloboda (Eds.), Handbook of Music and Emotion: Theory, Research, Applications (pp. 515-546). Oxford: Oxford University Press.

Heye, A, \& Lamont, A. (2010). Mobile listening situations in everyday life: The use of MP3 players while travelling. Musicae Scientiae, 14(1), 95-120. doi:10.1177/102986491001400104.

Hines, M, \& Mehrabian, A. (1979). Approach-avoidance behaviours as a function of pleasantness and arousing quality of settings and individual differences in stimulus screening. Social Behavior and Personality, 7(2), 223-233.

Juslin, PN, Liljeström, S, Västfjäll, D, Barradas, G, \& Silva, A. (2008). An experience sampling study of emotional reactions to music: Listener, music, and situation. Emotion, 8(5), 668-683. doi:10.1037/a0013505.

Kamalzadeh, M, Baur, D, \& Möller, T. (2012). A survey on music listening and management behaviours. In Proceedings of the 13th International Society for Music Information Retrieval Conference (ISMIR 2012), Porto, Portugal.

Kellaris, J. (1992). Consumer esthetics outside the lab: Preliminary report on a musical field study. Advances in Consumer Research, 19, 730-734.

Kibby, M. (2009). Collect yourself: Negotiating personal archives. Information, Communication \& Society, 12(3), 428-443. doi:10.1080/13691180802660644

Komulainen, S, Karukka, M, \& Hakkila, J. (2010). Social music services in teenage life - A case study. In S Viller \& B Kraal (Eds.), Proceedings of the 22nd Conference of the Computer-Human Interaction Special Interest Group of Australia on Computer-Human Interaction, OZCH'10, November 22-26, 2010 (pp. 364-367). doi:10.1145/1952222.1952303.

Krause, AE. (2010). myTunes: Digital music library users and their self images (Unpublished masters thesis). London UK: Roehampton Unversity.

Krause, AE, North, AC, \& Hewitt, LY. (2013). Music listening in everyday life: Devices and choice. Psychology of Music Advance online publication. doi:10.1177/0305735613496860.

Krause, AE, North, AC, \& Hewitt, LY. (2014). Music selection behaviors in everyday listening. Journal of Broadcasting and Electronic Media, 58(2), 306-323. doi:10.1080/08838151.2014.906437.

Krause, AE, North, AC, \& Hewitt, LY. (2014). The role of location in everyday experiences of music. Psychology of Popular Media Culture.

Leong, TW, \& Gram, N. (2011). The creative iPod listener (Paper presented at the 17th Interantional Symposium on Electronic Art, Istanbul). Retrieved from http://isea2011.sabanciuniv.edu/paper/creative-ipod-listener.

Leong, TW, \& Wright, P. (2013). Revisiting social practices surrounding music. In Proceedings of the SIGCHI Conference on Human Factors in Computing Systems (pp. 951-960). New York, NY: ACM. doi:10.1145/2470654.2466122.

Mehrabian, A, \& Russell, JA. (1974). An approach to environmental psychology. Cambridge, MA, USA: Massachusetts Institute of Technology.

Molteni, L, \& Ordanini, A. (2003). Consumption patterns, digital technology and music downloading. Long Range Planning, 36(4), 389-406. doi:10.1016/50024-6301(03)00073-6.

North, AC. (2010). Individual differences in musical taste. The American Journal of Psychology, 123(2), 199-208. doi:10.5406/amerjpsyc.123.2.0199.

North, AC, \& Davidson, JW. (2013). Musical taste, employment, education, and global region. Scandinavian Journal of Psychology, 54, 432-441. doi:10.1111/sjop.12065.

North, AC, \& Hargraves, DJ. (1997). Experimental aesthetics and everyday music listening. In DJ Hargreaves \& AC North (Eds.), The social psychology of music (pp. 84-103). Oxford, UK: Oxford University Press.

North, AC, \& Hargreaves, DJ. (1996a). The effects of music on responses to a dining area. Journal of Environmental Psychology, 16(1), 55-64. doi:10.1006/jevp.1996.0005.

North, AC, \& Hargreaves, DJ. (1996b). Responses to music in aerobic exercise and yogic relaxation classes. British Journal of Psychology, 87, 535-547.

North, AC, \& Hargreaves, DJ. (1996c). Situational influences on reported musical preference. Psychomusicology, 15, 30-45.

North, AC, \& Hargreaves, DJ. (2000). Musical preferences during and after relaxation and exercise. American Journal of Psychology, 113(1), 43-67.

North, AC, \& Hargreaves, DJ. (2008). The social and applied psychology of music. Oxford: Oxford University Press.

North, AC, Hargreaves, DJ, \& Hargreaves, JJ. (2004). Uses of music in everyday life. Music Perception, 22(1), 41-77. doi:10.1525/mp.2004.22.1.41

Sloboda, JA, \& Juslin, PN. (2010). At the interface between the inner and outer world: Psychological perspectives. In Handbook of music and emotion: Theory, research, applications (pp. 73-97). New York, NY: Oxford University Press. US.

Sloboda, JA, Lamont, A, \& Greasley, AE. (2009). Choosing to hear music: Motivation, process, and effect. In S Hallam, I Cross, \& M Thaut (Eds.), The Oxford Handbook of Music Psychology (pp. 431-440). Oxford: Oxford University Press.

Stumpf, S, \& Muscroft, S. (2011). When users generate music playlists: When words leave off, music begins? In Proceedings of ICME 2011 (pp. 1-6).

Yalch, RF, \& Spangenberg, ER. (2000). The effects of music in a retail setting on real and perceived shopping times. Journal of Business Research, 49(2), 139-147. doi:10.1016/S0148-2963(99)00003-X.

Yani-de-Soriano, MM, \& Foxall, GR. (2006). The emotional power of place: The fall and rise of dominance in retail research. Journal of Retailing and Consumer Services, 13, 403-441. doi:10.1016/j.jretconser.2006.02.007.

doi:10.1186/s13612-014-0022-7

Cite this article as: Krause and North: Contextualized music listening: playlists and the Mehrabian and Russell model. Psychology of Well-Being: Theory, Research and Practice 2014 4:22. 